\title{
Visualization of the air flow behind the automotive benchmark vent
}

\author{
Ondrej Pech ${ }^{1,}$, Jan Jedelsky $^{1}$, Petr Caletka $^{1}$ and Miroslav Jicha ${ }^{1}$ \\ ${ }^{1}$ Brno University of Technology, Faculty of Mechanical Engineering, Technicka 2896/2, Brno, Czech Republic
}

\begin{abstract}
Passenger comfort in cars depends on appropriate function of the cabin HVAC system. A great attention is therefore paid to the effective function of automotive vents and proper formation of the flow behind the ventilation outlet. The article deals with the visualization of air flow from the automotive benchmark vent. The visualization was made for two different shapes of the inlet channel connected to the benchmark vent. The smoke visualization with the laser knife was used. The influence of the shape of the inlet channel to the airflow direction, its enlargement and position of air flow axis were investigated.
\end{abstract}

\section{Introduction}

Human comfort in new cars, where thermal comfort plays an important role, is of prime importance nowadays. The climate control of the passenger cabin is driven by the HVAC system and its components. The HVAC system is continuously improved to be more effective. However, the design of the car cabin and its dashboard provides less space available for the inlet ductwork that brings the air to the car cabin. Due to this reason it is also difficult to design proper shapes of the air vents which affect the air flow behind the air vents. Lin [1] carried out the experimental and computational studies of flow in a simplified HVAC duct, Kuznik [2] investigated the impact of inlet boundary conditions on CFD modelling of the ventilation system with different shapes of the duct. Kreuzinger [3] studied the outlet jet in a car air conditioning system with use of Large Eddy Simulation. Singh [4] studied the air flow through the double offset transition S-Duct with diffusion and Lezovic $[5,6]$ studied the air flow from a vent mounted on a side of the dashboard using the CTA (Constant Temperature Anemometry) measurements.

This paper deals with the visualization of air flow from the outlet element of the car ventilation system, which is virtually the adjustable air channel and the benchmark vent (a specially designed automotive vent of the car dashboard, see Figure 1). The influence of the shape of the inlet channel to the airflow direction, its enlargement and position of air flow axis were observed.

\section{Experimental set-up}

The experimental set-up (figure 2 and 4 ) consists of three main parts: air inlet, flow measurement and visualization part. It was located in a laboratory room of dimensions
$\mathrm{L} \times \mathrm{W} \times \mathrm{H}=8.4 \times 4.7 \times 3.2 \mathrm{~m}$ and the benchmark vent was placed in a sufficient distance from the walls of the laboratory to avoid their influence on the stream leaving the vent, see Awbi [7]. The smoke from the smoke generator (position 18 in Figure 4) and the air from the laboratory were sucked into the fan (position 3 ). The barometric pressure, temperature and humidity in laboratory were recorded using the Comet T7418 apparatus. The temperatures in the ventilation system inlet and in front of the orifice plate flowmeter were measured with the use of Pt100 resistance thermometers.

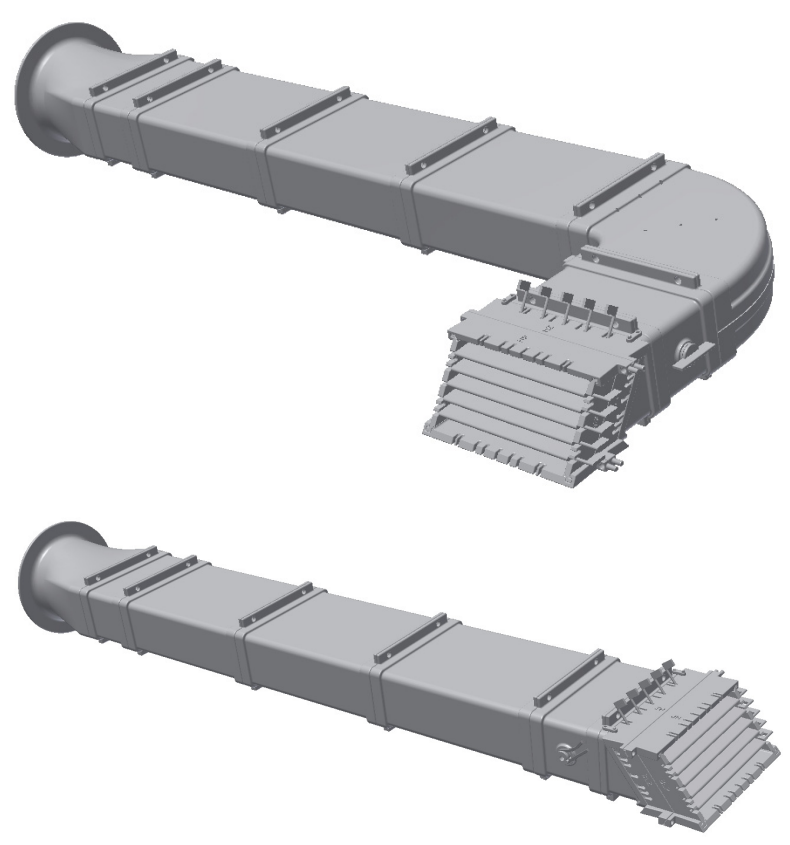

Figure 1. 3D model of the benchmark vent with and without the elbow.

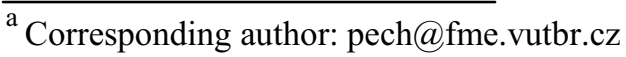


The pressure in front of the orifice plate and the difference pressure of the orifice plate were taken with the use of two Airflow PTSXR-K pressure transmitters. The air flow was determined according to CSN EN ISO 5167 standard.

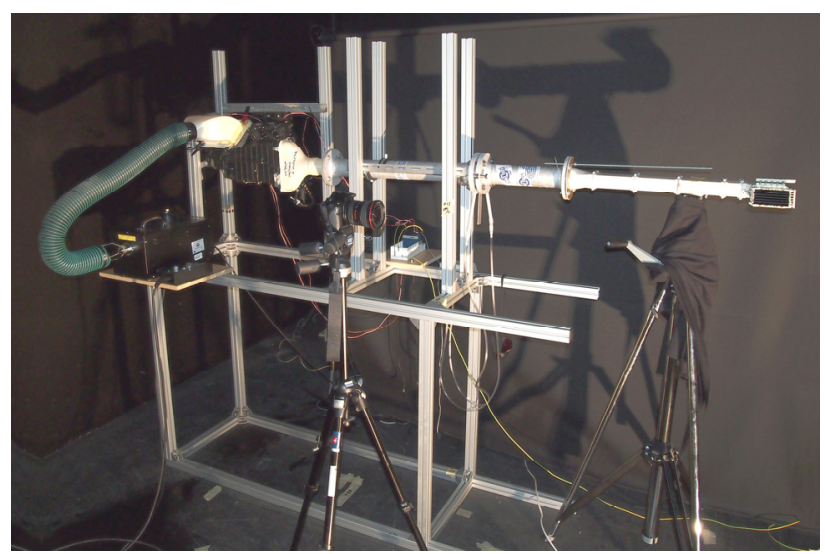

Figure 2. The experimental set-up.

For the visualization study, the Safex 195 SG smoke generator and the laser knife with the wavelength of $532 \mathrm{~nm}$ and the maximal output power of $2 \mathrm{~W}$ were used. Images of the smoke illuminated by the light sheet were taken by Canon EOS 300D with the lens Canon EF 17$40 \mathrm{~mm} \mathrm{f} / 4 \mathrm{~L}$ USM. The lens of the camera was always positioned perpendicularly to the light sheet.

The outlet element of the airflow part is the assembly of the adjustable air channel, air channel elbow, air flap and the main part is the benchmark vent (positions 7, 8, 9, 10 in Figure 4). All those parts are made by rapid prototyping technology (Figure 1). The air flap is symmetric with the horizontal axis of rotation and it can be set in the range between $-90^{\circ}$ to $90^{\circ}$. The benchmark vent type enables to modify the number of vertical and horizontal vanes between 3 and 5 pieces and their order (first internal row of vertical vanes, second external row of horizontal vanes or conversely) can also be set. The vertical and the horizontal vanes can be set in the range between $-45^{\circ}$ and $45^{\circ}$. The cross-section area of the vent outlet is $48.45 \mathrm{~cm}^{2}$.

\section{Methodologies}

In the experiments the benchmark vent comprises 5 vertical vanes and 5 horizontal vanes. The first was the internal row of vertical vanes; the second was the external row of horizontal vanes.
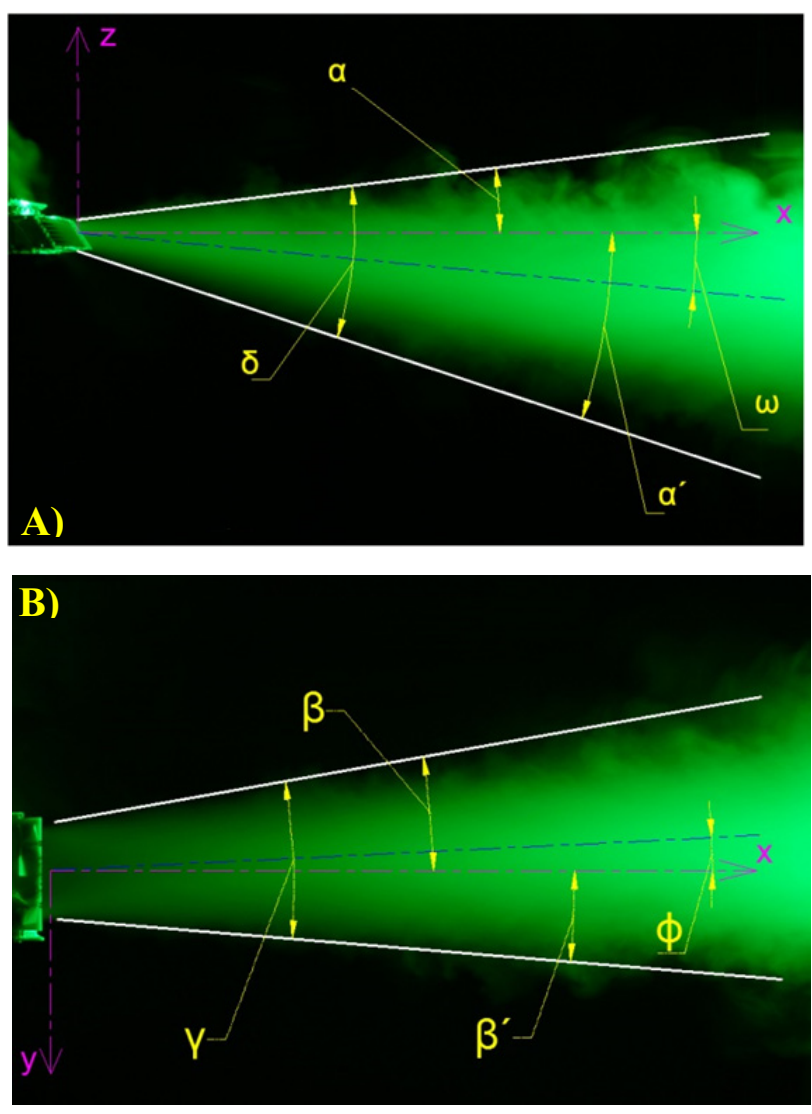

Figure 3. Coordinate system and orientation of the angles A) side view B) bottom view

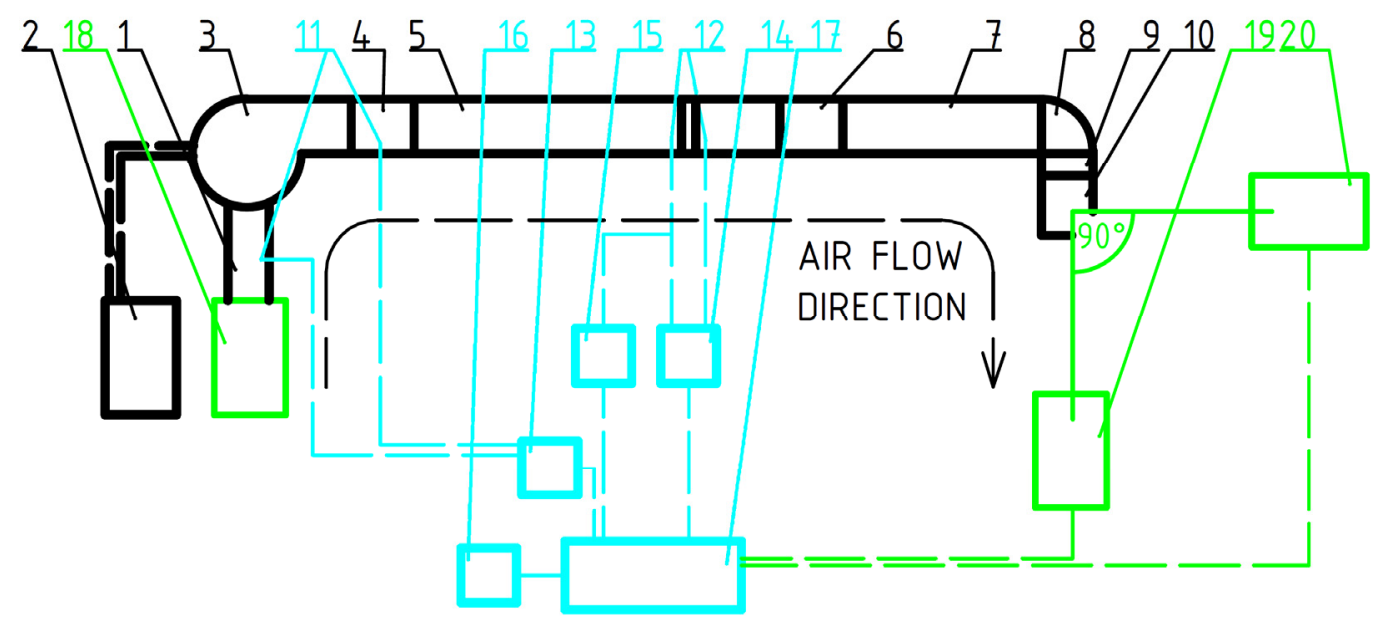

Figure 4. The scheme of the measurement set-up.

1 - inlet duct, 2 - power supply, 3 - fan, 4 - reduction, 5 - orifice plate flowmeter, 6 - reduction, 7 - adjustable air channel, 8 - air channel elbow, 9 - air flap, 10 - benchmark vent, 11 - temperature sensors Pt100, 12 - pressure measurement,

13 - temperature measurement module, 14,15 - pressure transmitters, 16 - temperature, humidity and barometric pressure transmitters, 17 - PC, 18 - smoke generator, 19 - laser knife, 20 - camera. 
The vertical and horizontal vanes were fixed in the central position (the angle of $0^{\circ}$ ). The flap was set to its horizontal position, i.e. fully open flap. The coordinate system of the benchmark vent is shown in figure 3: the $\mathrm{X}$-coordinate pointing horizontally, the Y-coordinate pointing horizontally and the Z-coordinate pointing vertically. The coordinate system also defines the orientation of the angles, see figure 3 . The airflow rate through the benchmark vent was set to $33.5 \mathrm{~m}^{3} \cdot \mathrm{h}^{-1}$. The volume flow rate of the smoke fluid to the smoke generator was set to $10 \mathrm{ml} \cdot \mathrm{min}^{-1}$. The output power of the laser knife was set to $0.8 \mathrm{~W}$ and its light sheet was positioned to the axis of the air stream.

The images of the air stream were taken in the planes $\mathrm{XZ}$ and XY. In total, 20 images in each plane with the frequency of $2 \mathrm{~s}$ and with the exposure time of $1 \mathrm{~s}$ were taken. The images were analysed according to changes of the luminance intensity by the local threshold method, see Richter [8]. This method is resistant to disturbances at boundaries of the stream. As the reference value of the method the $50 \%$ of the minimum luminance intensity in the axis of flow in the reference image was used. Finally, the angles between the stream boundaries and the stream axis were determined.

\section{Results and discussion}

The assessment of the stream relies on the determined stream boundaries and on the stream axis. As can be seen
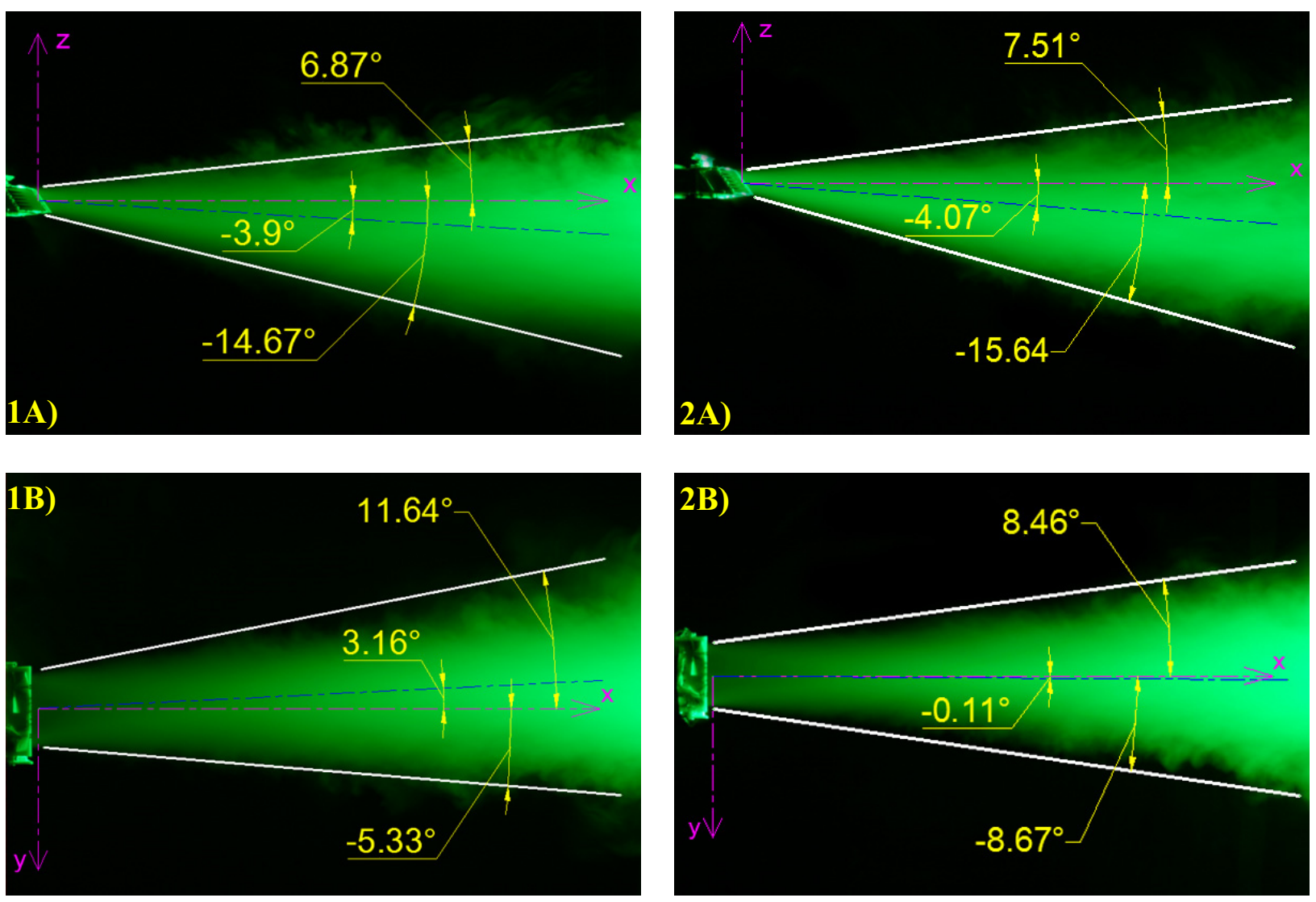

Figure 5. Smoke visualization of air flow from the benchmark vent: 1 - with elbow: A) side view plane XZ; B) A) bottom view plane XY 2 - without elbow: A) side view plane XZ; B) A) bottom view plane XY. 
As for the deviation angle $\phi$ in the $X Y$ plane (see visualization $2 \mathrm{~A}, 2 \mathrm{~B}$ in Figure 5), one can see a considerable discrepancy. Note the vertical vanes that direct the flow in the horizontal plane $\mathrm{XY}$ are adjusted to the angle $0^{\circ}$ but the actual flow direction in case with the elbow is $3.16^{\circ}$ in comparison with $-0.11^{\circ}$ in case without the elbow. The stream angle of the enlargement $\gamma$ is $16.97^{\circ}$ with the elbow and $17.13^{\circ}$ without the elbow. Note that all images were taken perpendicular to the plane of light sheet.

\section{Conclusions}

An experimental set-up for investigation of the airflow from the car vents was assembled and the initial sets of experiments were carried out. The adjustable air channel with the benchmark vent made by rapid prototyping technology was used as the outlet part of the air duct. The experiments were focused on the influence of the elbow in the inlet channel on the airflow direction, its enlargement and position of airflow axis. For this purpose the smoke visualization method with the laser knife was used.

The results show that in the plane $\mathrm{XZ}$ and in the case without the elbow, the stream angle of enlargement is slightly larger (of $1.61^{\circ}$ ) in comparison to the case with the elbow. There is no considerable influence of the elbow on the stream axis angle. It was also shown that the actual stream axis angle is deflected downwards in comparison with the vanes adjusted to the angle of $0^{\circ}$. In the XY plane, a considerable change of the deviation angle was shown in case with the elbow (the difference was $3.27^{\circ}$ ) which is the main consequence of the elbow. This influence of the elbow can be eliminated with the use of the rectifying vanes in the elbow.

\section{Acknowledgements}

This work was supported by the internal Brno University of Technology research project Reg. No. FSI-S-14-2355, and by research and scientific activities of NETME Centre, regional R\&D centre built with the financial support from the Operational Programme Research and Development for Innovations within the project NETME Centre (New Technologies for Mechanical Engineering), Reg. No. CZ.1.05/2.1.00/01.0002 and, in the follow-up sustainability stage, supported through NETME CENTRE PLUS (LO1202) by financial means from the Ministry of Education, Youth and Sports of the Czech Republic under the „National Sustainability Programme I'. The authors also gratefully acknowledge the support from the "Josef Bozek Competence Centre for Automotive Industry", number TE01020020 of the Technology agency of the Czech Republic.

\section{References}

1. C. H. Lin, T. Y. Han, V. Sumantran, IJVD, 15, 18, (1994)

2. F. Kuznik, J. Brau, IJV, 4, 9, (2005)
3. J. Kreuzinger, A. Le Duc, N. Peller, M. Manhart, E. P. Wachsmann, Euromech 471, 3, (2005)

4. R. K. Singh, S. Singh, V. Seshadri, IJCM, 5, 19, (2008)

5. T. Lezovic, F. Lizal, J. Jedelsky, M. Jicha, EPJ Web of Conferences, 25, 10, (2012)

6. T. Lezovic, F. Lizal, J. Jedelsky, M. Jicha, HVAC\&R Research, 19, 9, (2013)

7. H. B. Awbi, Ventilation of buildings, 536, (2003)

8. J. Richter, J. Stastny, Advances in Computer Science, $6,(2012)$ 